\title{
Program Kemitraan Masyarakat: Pembuatan Identitas Merek dan Pembinaan Penerapan Branding untuk Meningkatkan Penjualan Usaha Mikro Kuliner Kupat Tahu Padalarang di Kecamatan Batujajar
}

Tintin Suhaeni ${ }^{1}$, Sri Raharso ${ }^{2}$, Ivon Sandya Sari Putri ${ }^{3}$, Abdul Malik Sayuti ${ }^{4}$, Tangguh Dwi Pramono $^{5}$, Marceilla Suryana ${ }^{6}$, Chandra Budhi Septiyandi ${ }^{7}$

\author{
${ }^{1,2,3,4}$ Program Studi Sarjana Terapan Administrasi Bisnis, Jurusan Administrasi Niaga, Politeknik Negeri \\ Bandung, Jalan Gegerkalong Hilir, Kabupaten Bandung Barat, Indonesia \\ ${ }^{5}$ Program Studi Ahli Madya Administrasi Bisnis, Jurusan Administrasi Niaga, Politeknik Negeri \\ Bandung, Jalan Gegerkalong Hilir, Kabupaten Bandung Barat, Indonesia \\ ${ }^{6,7}$ Program Studi Ahli Madya Usaha Perjalanan Wisata, Jurusan Administrasi Niaga, Politeknik Negeri \\ Bandung, Jalan Gegerkalong Hilir, Kabupaten Bandung Barat, Indonesia
}

\begin{abstract}
This community partnership program aims to develop the Kupat Tahu Padalarang business in Kecamatan Batujajar, Jawa Barat by building a business brand identity, personal branding, excellent service, and good customer communication. The survey was conducted to obtain information on brand awareness, business conditions, and customer satisfaction before and after the program was implemented. The creation of a business brand identity starts with creating logo, banner, product packaging, employee uniforms, and structuring the business environment. Personal branding itself is created through the development of excellent service and good and friendly customer communication. Business brands that have been created have also been registered to protect business actors from imitating them. The brand is a capital that can be developed by business actors to be used in promotion on social media in order to increase business brand equity.
\end{abstract}

Abstrak - Program kemitraan masyarakat ini bertujuan mengembangkan usaha kupat tahu padalarang di Kecamatan Batujajar, Jawa Barat dengan cara membangun identitas merek usaha, personal branding, pelayanan prima, dan komunikasi pelanggan yang baik. Pelaksanaan survey dilakukan untuk mendapatkan informasi tentang kesadaran merek, kondisi usaha, dan kepuasan pelanggan sebelum dan sesudah program dijalankan. Penciptaan identitas merek usaha dimulai dari membuat logo, spanduk, kemasan produk, seragam karyawan, dan penataan lingkungan tempat usaha. Personal branding sendiri diciptakan melalui pembangunan pelayanan prima dan komunikasi pelanggan yang baik dan ramah. Merek usaha yang telah diciptakan pun telah terdaftar guna melindungi pelaku usaha dari perilaku tiru meniru competitor lain. Merek tersebut menjadi modal yang dapat dikembangkan pelaku usaha untuk dapat dipergunakan dalam promosi di media sosial guna meningkatkan brand equity usaha.

Kata Kunci-Identitas merek, Personal Branding, Pelayanan Prima, Komunikasi Pelanggan

\section{PENDAhUluan}

Sektor usaha mikro mempunyai peranan yang cukup besar di Indonesia. Dikutip dari okezone.com, menurut Ketua Asosiasi UMKM Indonesia, Muhammad Ikhsan Ingratubun, data per 2018 sektor UMKM menyumbang Rp 8.400 triliun terhadap Produk Domestik Bruto (PDB) 
dan untuk tenaga kerja, UMKM berhasil menyerap 121 juta tenaga kerja. Menurut Badan Pusat Statistik Jawa Barat Ttahun 2018, usaha mikro di bidang kuliner di Jawa Barat sendiri telah menyerap 1,5 juta tenaga kerja. Salah satu jenis usaha kuliner mikro sendiri adalah usaha kupat tahu Padalarang yang merupakan kuliner khas di Jawa Barat khususnya di daerah Kota Bandung dan sekitarnya.

Sebagai kuliner yang dikenal untuk sarapan pagi, kupat tahu Padalarang ini dapat ditemui di sepanjang jalan Bandung dan sekitarnya, khususnya di Jalan Batujajar, Kabupaten Bandung Barat. Dengan kualitas rasa dan harga yang berbeda-beda, satu hal yang menjadi persamaan, para pelaku usaha tersebut tidak mempunyai identitas merek yang jelas yang dapat membedakan mereka satu sama lain. Padahal identitas merek dapat menjadi investasi usaha dalam meningkatkan kualitas dari produk yang mereka jual sehingga mendapatkan keuntungan yang tinggi (Agostini, et.al., 2015).

Penciptaan identitas merek pada usaha mikro kuliner ini masih dipandang tidak penting dalam usaha. Pelaku usaha mikro kuliner ini hanya beranggapan hal penting hanya menjual produk yang enak dan berkualitas sehingga setiap hari pembeli datang. Padahal, identitas merek yang kuat dapat menciptakan persepsi yang positif di mata konsumen tentang usaha mereka dan menjadi modal bila mereka ingin melakukan ekspansi. Dapat diambil contoh salah satu usaha kuliner mikro yang kini berekspansi yaitu Bebek Goreng "H. Slamet" Kartasura dengan 34 cabang di seluruh Indonesia. Usaha ini berawal dari warung dengan gerobak khas "Lamonganan" dimana semua orang dapat masuk ke dalam bisnis ini. Namun, dengan identitas merek usaha yang unik dan kuat, usaha mikro tersebut kini telah berkembang menjadi "rantai warung makan".

Potensi ekspansi bisnis kupat tahu Padalarang dapat terjadi dengan adanya kesadaran untuk menciptakan identitas merek yang kuat dan menjadi salah satu orientasi bisnis para pelaku usaha kupat tahu Padalarang. Potensi yang dapat tercipta jika usaha mereka sukses adalah penyerapan tenaga kerja di lingkungan sekitar yang juga akan meningkat. Usaha kuliner merupakan usaha yang relative stabil, pembelinya selalu ada, bahkan di masa krisis pandemic seperti sekarang ini.

Belum ada pemahaman dan penerapan branding yang jelas untuk mengembangkan usaha mikro para mitra, sehingga usaha untuk menarik konsumen dan meningkatkan loyalitas pelanggan masih kurang maksimal. Program kemitraan ini bertujuan untuk membangun identitas merek yang unik, mulai dari nama merek, logo usaha, desain kemasan, serta seragam karyawan. Lalu diberikan pula petunjuk praktik yang jelas mengenai komunikasi kepada pelanggan dan personal branding yang bertujuan untuk meningkatkan brand awareness 
pelanggan dan kualitas pelayanan pedagang, yang diharapkan akan bermuara pada peningkatan loyalitas pelanggan nantinya.

Branding sendiri lebih didominasi dilakukan oleh bisnis besar. Usaha mikro terpantau tidak peduli terhadap pentingnya branding karena biasanya mereka mempunyai kelemahan dalam faktor finansial sehingga branding sangat terbatas dilakukan oleh mereka (Wong \& Merriless, 2005). Padahal branding merupakan sumber daya kunci yang menjadikan organisasi sukses dalam jangka panjang (Abimbola \& Kocak, 2007). UMKM sendiri biasanya mempunyai karakteristik organisasi yang informal, inovatif, kreatif, namun mempunyai kekurangan dalam perencanaan keuangan, sumber daya, dan pengalaman (Krake, 2005; Centeno, et.al., 2013).

\section{TINJAUAN PUSTAKA}

Identitas merek adalah sesuatu hal yang nyata dan dapat dilihat, disentuh, dipegang, didengar, dan bergerak berkenaan tentang merek bisnis. Identitas merek membuat rekognisi dan perbedaan yang jelas dengan para competitor. Identitas merek dapat meliputi logo, warna, layout, desain kemasan, desain web dan sebagainya. Semua hal yang dapat dilihat dari sebuah merek usaha, disebut identitas merek (Wheeler, 2018).

Penerapan instrument kreatif dalam hal identitas merek seperti paten, merek dagang, nama, simbol dan logo yang bereputasi baik dapat meningkatkan basis pasar dari usaha mikro. Nama merek dapat menjadi alat komunikasi antara usaha dan konsumen, untuk menginformasikan nilai lebih usaha mereka dan pembeda dari kompetitor (Abimbola, 2001). Merek yang kuat memiliki pengaruh yang tinggi dalam hal keputusan pembelian, sebagai identitas dari perusahaan, merupakan pembeda produk satu dengan yang lain, membangun persepsi konsumen terhadap suatu produk, serta memberikan alasan bagi konsumen untuk melakukan pembelian. Adapun elemen-elemen penting dasar saat membangun identitas merek adalah sebagai berikut (Seimiene \& Kamarauskaite, 2018; Farhana, 2012):

a. Nama merek; elemen ini merupakan informasi yang paling terlihat oleh pelanggan dan menjadi basis bagi brand awareness dan komunikasi pelanggan. Penamaan merek hendaknya sederhana, mudah dieja oleh pelanggan, familiar, serta memiliki makna dan kekhasan agar meningkatkan ketertarikan dan pengakuan dari pelanggan. Nama merek harus mengesankan dan memperkuat asosiasi manfaat produk yang ditawarkan.

b. Logo/ Simbol; merupakan elemen penting lain bagi identitas visual merek yang digunakan oleh penjual. Desain logo mempengaruhi persepsi pelanggan atas brand personality yang penjual miliki. Logo harus dikembangkan agar mudah diingat, mudah dikenali, dan terlihat. 
c. Warna; pemilihan warna dapat memberikan banyak arti kepada pelanggan. Misalnya, warna merah dipersepsikan sebagai kualitas yang tinggi dan cinta, atau warna kuning sebagai simbol dari kebahagiaan.

d. Kemasan; unsur estetika dan fungsional dari kemasan harus diperhatikan dengan baik, disesuaikan dengan positioning dan target penjualan produk. Hal-hal yang perlu diperhatikan dalam membuat kemasan adalah ukuran, pola, material, warna, tulisan dan gambar inovatif yang mampu menarik minat pelanggan untuk membeli. Kemasan tidak hanya melindungi higienitas produk tetapi juga dapat mengkomunikasikan manfaat emosional, rasional, maupun fungsional dari produk yang ditawarkan.

Dalam usaha mikro, tipe branding yang dapat digunakan adalah personal branding yaitu dimana para pengusaha menjadikan karakter pribadi mereka untuk meningkatkan reputasi usaha mereka sendiri. Branding dapat dilakukan salah satunya melalui promosi dan/atau iklan (Wheeler, 2018). Branding dilihat penting bagi strategi dan operasi usaha mikro, namun para pelaku usaha mikro lebih sibuk memikirkan operasional sehari-hari ketimbang memikirkan tentang merek (Cant et.al., 2013).

\section{METODE}

Bagian ini menjelaskan tentang metode atau prosedur pengabdian yang dilaksanakan. Metode atau prosedur yang dilaksanakan dalam program kemitraan untuk mengatasi permasalahan mengenai identitas merek pedagang kupat tahu padalarang di Batujajar meliputi tiga proses yaitu tahap persiapan, tahap pelaksanaan, dan terakhir tahap evaluasi.

\subsection{Tahap Persiapan}

Pada tahap persiapan ini, dilakukan wawancara dengan pemilik dan pegawai usaha kupat tahu Padalarang yang menjadi mitra binaan terkait pemahaman mereka tentang pentingnya identitas usaha seperti nama merek, logo, simbol, identitas visual lainnya dan kemasan produk yang digunakan dalam meningkatkan kualitas dan meningkatkan loyalitas pelanggan. Wawancara dilakukan bertahap dengan sesi pertama melalui telepon, dan pada sesi kedua dilakukan melalui tatap muka dengan memperhatikan protokol pencegahan penularan Covid-19 dari pemerintah. Selanjutnya, tim melakukan identifikasi jumlah kebutuhan peralatan dan perlengkapan untuk pembangunan identitas merek yang akan dilakukan, seperti keinginan pedagang kupat tahu Padalarang terkait nama merek dagang, logo yang diinginkan, jumlah kemasan produk yang akan diproduksi, baju seragam serta upron yang dibutuhkan oleh mitra binaan. 
Untuk mengidentifikasi tingkat brand equity dalam rangka mengetahui kuat lemahnya posisi mereka di mata konsumen, tim melakukan survey sederhana. Survey ini dilakukan menggunakan google form dan sebagian melalui pembagian kuesioner manual terhadap konsumen yang datang membeli.

\subsection{Tahap Pelaksanaan}

Didalam pelaksanaan program kemitraan ini, tim dan para mitra menentukan identitas merek usaha dagang, yaitu nama merek usaha, logo yang akan digunakan, desain kemasan, seragam dan upron yang akan digunakan. Dalam hal merancang logo, tim bekerjasama dengan tim professional lainnya dalam hal mendesain logo. Kemudian, tim mengatur lingkungan usaha mitra guna meningkatkan pelayanan konsumen sebagai salah satu bentuk usaha dalam branding. Tahap ini dilakukan dengan cara berkunjung langsung ke lapangan.

Setelah identitas merek usaha dan lingkungan usaha mitra dibina dengan baik, para mitra diberikan pendampingan praktik mengenai bagaimana cara membina hubungan baik dengan konsumen secara langsung dan melalui media sosial sebagai bentuk personal branding. Media sosial yang digunakan adalah Instagram.

Selain itu, tim juga memberikan pelayanan konsultasi bagi mitra binaan yang kesulitan dalam pembangunan identitas merek usaha dan branding. Tim membantu mitra untuk mendaftarkan merek dagang mereka ke Dirjen Kekayaan Intelektual.

\subsection{Tahap Evaluasi}

Evaluasi pelaksanaan program kemitraan masyarakat ini dilakukan dengan wawancara untuk melihat perbedaan perjalanan bisnis sebelum dan sesudah program dijalankan. Selain itu, dilakukan wawancara terhadap mitra untuk memastikan pemahaman mereka terhadap proses personal branding. Karena proses terciptanya merek usaha yang kuat tidak tercipta secara cepat, membutuhkan waktu, maka tim akan tetap melayani konsultasi dengan mitra. Pengembangan merek merupakan evolusi yang terus berjalan. Media sosial yang digunakan untuk mempromosikan mitra akan tetap dipelihara, agar bisnis mereka dikenal oleh masyarakat. Hal ini dilakukan agar mitra tetap berorientasi pada strategi branding, sehingga keberlanjutan program akan terjaga.

\section{IV.HASIL DAN PEMBAHASAN}

Program kemitraan ini dimulai pada bulan Maret hingga September 2020, yang dimulai dari identifikasi permasalahan mitra hingga, pelaksanaan program dan evaluasi. Para mitra merupakan pedagang kupat tahu Padalarang yang tidak mempunyai latar pendidikan tinggi dalam bidang bisnis maupun pelayanan pelanggan. Para mitra juga belum pernah mendapatkan 
pengetahuan bagaimana cara \& pentingnya menciptakan identitas merek dalam pengembangan usaha kuliner dari pihak manapun. Tim berhasil melaksanakan program penciptaan identitas merek usaha kupat tahu Padalarang, lalu mendampingi dalam hal personal branding dan promosi menggunakan media sosial Instagram.

Identifikasi kebutuhan identitas merek usaha bagi para mitra telah didiskusikan bersama dengan tenaga professional dibidang desain logo dan kemasan. Adapun hasil identitas merek usaha yang telah diciptakan dalam program ini seperti terlihat pada gambar-gambar berikut.
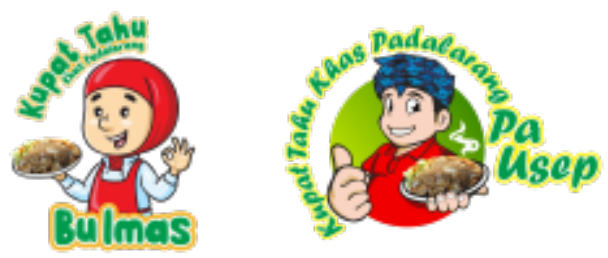

Gambar 1. Logo Usaha Mitra
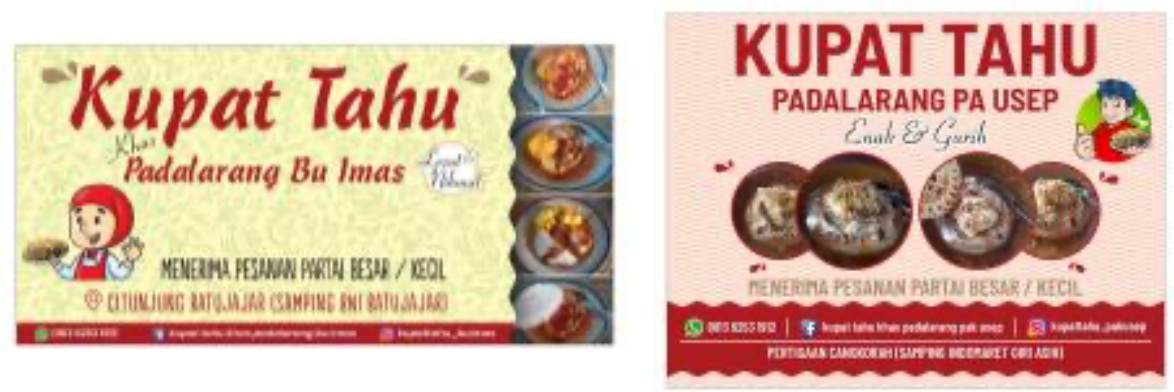

Gambar 2. Desain Spanduk Usaha
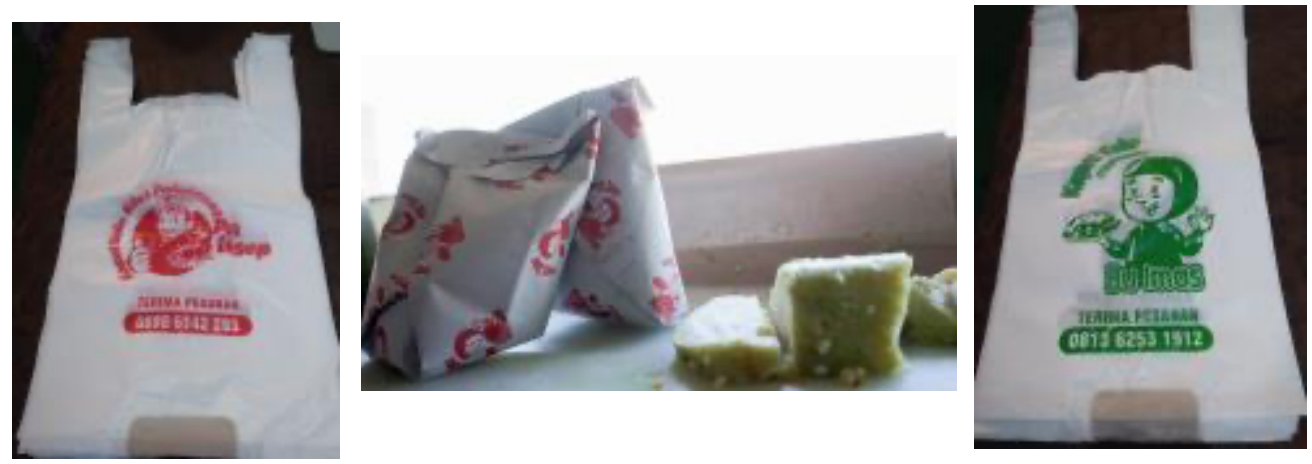

Gambar 3. Desain Kemasan Produk 


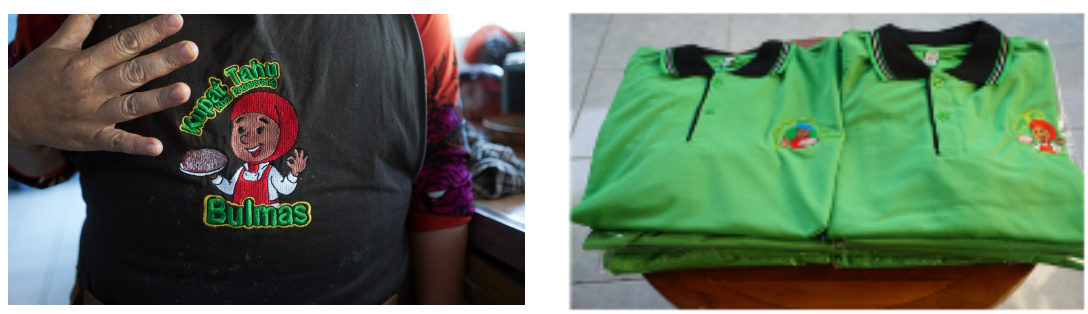

Gambar 4. Seragam dan Upron Karyawan
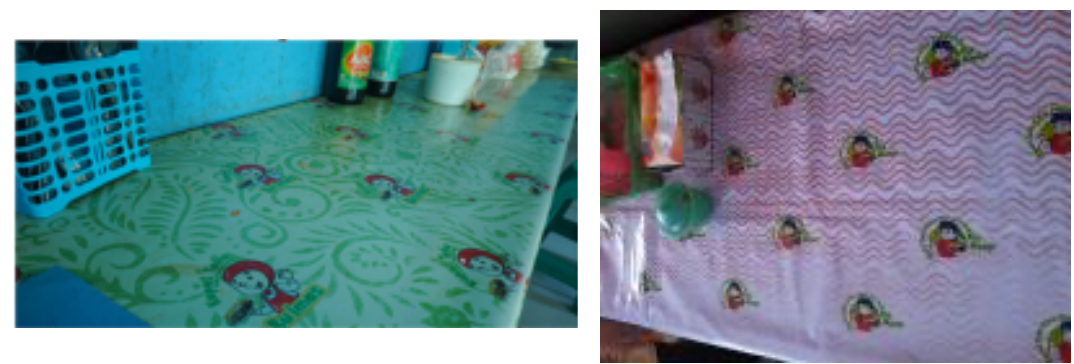

Gambar 5. Penataan Layout Warung Usaha

Dalam pra-survei, kami mengidentifikasi bahwa persepsi konsumen terhadap kualitas penataan dan kebersihan warung masih rendah. Oleh sebab itu dilakukan pengaturan lingkungan usaha mitra fokus pada penataan tempat supaya ergonomis, penataan kembali peralatan memasak produk kupat tahu, kompor, panci, display produk, piring, sendok, garpu, kecap, tempat sambal dan tempat cuci piring. Pengaturan tersebut dilakukan untuk memudahkan pelayanan sehingga pekerjaan dapat efektif dan efisien dalam melayani pelanggan.

Dalam hal personal branding dan komunikasi pelanggan melalui media sosial Instagram, telah dibuat dan dilakukan pendampingan dalam membuat konten media sosial untuk mempromosikan produk mitra. Pendampingan ini kami berikan kepada para mitra bersama anak/istri mitra yang lebih luwes dalam menggunakan media sosial. Anak/istri mitra tersebut turut membantu dalam usaha kuliner ini. Gambar 6 merupakan contoh halaman media sosial Instagram yang digunakan untuk promosi.

Dalam program kemitraan ini, terdapat IPTEK yang kami transferkan kepada para mitra yaitu pengetahuan bagaimana cara membuat dan pentingnya identitas merek. Kami juga memberikan model komunikasi dan pelayanan pelanggan yang baik, terutama dalam industri kuliner. Hal tersebut sudah mereka rasakan manfaatnya dengan adanya pujian dari pelanggan mengenai usaha mereka, membandingkan antara sebelum dan sesudah berjalannya program. 


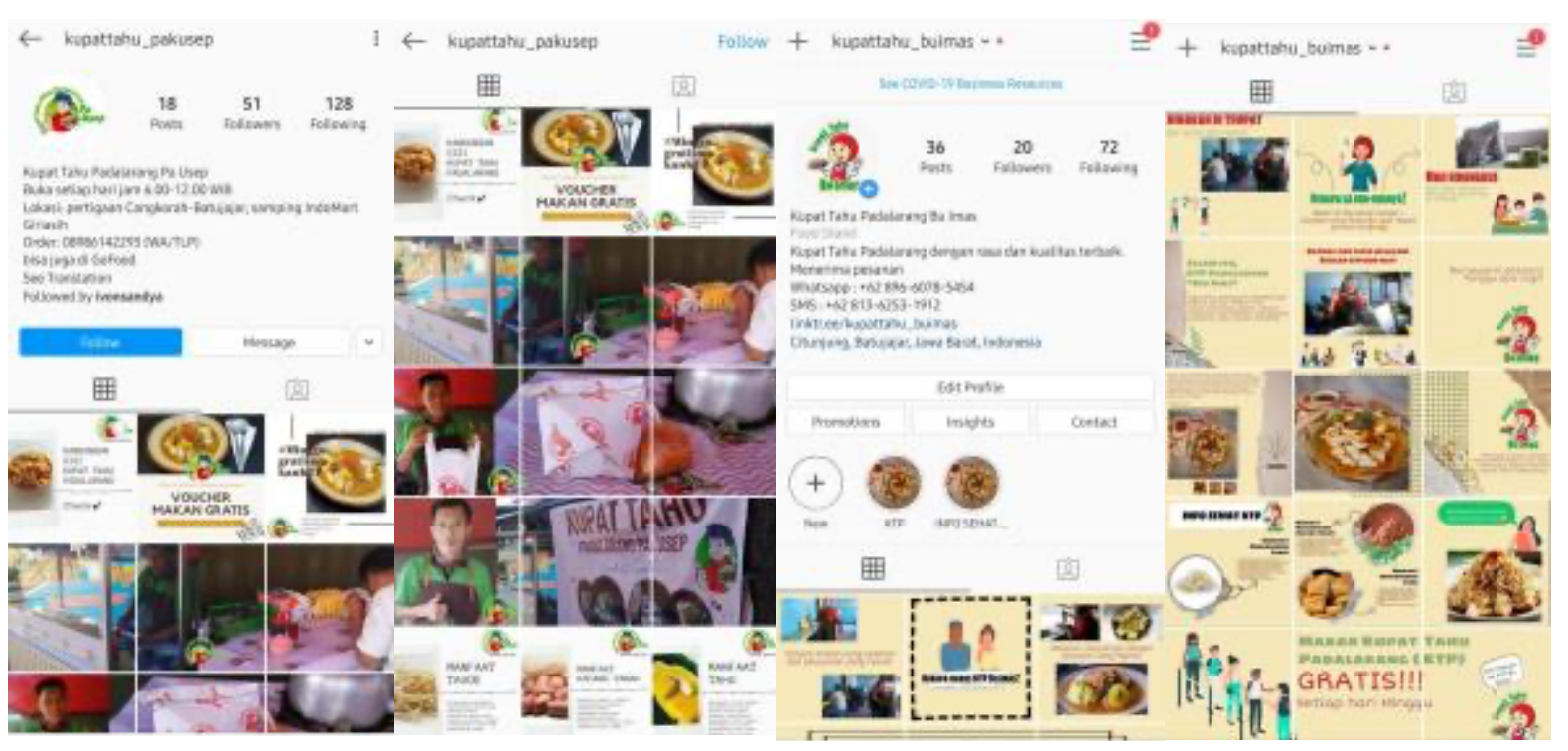

Gambar 6. Instagram Mitra Usaha

Kami melakukan survei sebelum dan sesudah program dijalankan mengenai bagaimana tingkat kesadaran merek dan loyalitas merek usaha kupat tahu padalarang di Batujajar kepada 63 responden. Tingkat kesadaran merek diukur berdasarkan lima pernyataan (contoh:"Saya mengenal warung kupat tahu Padalarang ini dengan baik") menggunakan empat skala, sedangkan loyalitas merek diukur berdasarkan 8 pernyataan (contoh: "Saya tidak akan membeli kupat tahu Padalarang dari warung lain, selama warung ini masih buka”) dengan skala yang sama. Hasil menunjukkan bahwa tingkat kesadaran merek meningkat $\left(\mathrm{M}_{\mathrm{awal}}=2.99 ; \mathrm{M}_{\mathrm{akhir}}=3.45\right)$ begitupun loyalitas merek $\left(\mathrm{M}_{\mathrm{awal}}=3.00 ; \mathrm{M}_{\mathrm{akhir}}=3.32\right)$. Berdasarkan hasil wawancara kepada pemilik usaha dan beberapa konsumen kupat tahu Padalarang, identitas merek usaha mitra sudah terlihat jelas dan dapat dibedakan dengan kompetitor. Setelah program ini dijalankan, peningkatan penjualan juga terjadi.

\section{KESIMPULAN}

Dari kegiatan-kegiatan yang telah dilakukan, dapat diambil kesimpulan bahwa program kemitraan ini berhasil meningkatkan brand awareness $\left(\mathrm{M}_{\mathrm{awal}}=2.99 ; \mathrm{M}_{\mathrm{akhir}}=3.45\right)$ dari usaha kupat tahu Padalarang di Batujajar dengan menciptakan identitas merek yang unik dan kuat serta membuat konten promosi dan personal branding melalui pelayanan prima dan komunikasi pelanggan baik secara langsung maupun menggunakan media sosial Instagram. Dari program ini juga didapatkan hasil bahwa penjualan para mitra pun meningkat seiring bertambahnya konsumen yang menyadari merek usaha mereka.

Kegiatan dalam hal peningkatan merek usaha tidak hanya sampai pada pembuatan identitas 
merek, melainkan perlu adanya penjagaan dan usaha-usaha lain untuk meningkatkan brand equity. Serta masih banyak hal dalam operasional bisnis mitra yang dapat digali untuk mereka bisa berkembang lebih baik. Untuk itu, program kemitraan masyarakat ini dapat dilanjutkan dengan lebih baik lagi kedepan dalam hal mengembangkan usaha mikro kupat tahu Padalarang ini.

\section{UCAPAN TERIMA KASIH}

Terima kasih disampaikan kepada semua pihak yang telah berkontribusi terhadap pelaksanaan kegiatan pengabdian kepada masyarakat, termasuk pihak yang memberikan pembiayaan atau kontribusi finansial untuk pelaksanaan kegiatan tersebut yaitu DIPA Politeknik Negeri Bandung. Tak lupa kami ucapkan terimakasih kepada Bapak Usep dan ibu Imas Solihah, yang telah aktif dan semangat berkomitmen dalam program kemitraan ini.

\section{DAFTAR PUSTAKA}

Abimbola, T. (2001). Branding as a Competitive Strategy for Demand Management in SMEs. Journal of Research in Marketing \& Entrepreneurship, 97-106.

Abimbola, T., \& Kocak, A. (2007). Brand, organization identity and reputation: SMEs as expressive organizations: A resources-based perspective. Qualitative Market Research: An International Journal, 416-430.

Agostini, L., Filippini, R., \& Nosella, A. (2015). Brand-building efforts and their association with SME sales performance. Journal of Small Business Management, 161-173.

Barat, B. P. (2018). Potensi Usaha Mikro Kecil Provinsi Jawa Barat.

Cant, M. C., Wiid, J. A., \& Hung, Y.-T. (2013). The importance of branding for South African SMEs: An Exploratory Study. Corporate Ownership \& Control, 735-744.

Centeno, E., Hart, S., \& Dinnie, K. (2013). The five phases of SME brand-building. Journal of Brand Management, 445-457.

Farhana, M. (2012). Brand Elements Lead to Brand Equity: Differentiate or Die. Information Management and Business Review.

Hartomo, G. (den 19 Juni 2018). Oke Finance. Hämtat från OKEZONE: http://economy.okezone.com den 2 Maret 2020

Krake, F. (2005). Successful brand management in SMEs: a new theory and practical hints. Journal of Product and Brand Management, 228-238. 
Seimiene, E., \& Kamarauskaite, E. (2014). Effect of Brand Elements on Brand Personality Perception. 19th International Scientific Conference: Economics and Management. Latvia.

Wheeler, A. (2018). Designing Brand Identity fifth edition. New Jersey: John Wiley \& Sons, Inc.

Wong, H. Y., \& Merrilees, B. (2005). A brand orientation typology for SMEs: a case research approach. Journal of Product \& Brand Management, 155-162. 